\title{
Rapid Improvement of Cranial Neuropathies after Endoscopic Resection of Sphenoid Sinus Mucocele
}

\author{
Alan Siu, M.D., ${ }^{1}$ Ameet Singh, M.D., ${ }^{2}$ and Fabio Roberti, M.D. ${ }^{1}$
}

Sinus mucoceles are benign, slowly enlarging, mucous-secreting, cystic lesions whose expansile growth may lead to compressive neuropathies. We present the case of a 70year-old woman with a long-standing history of headaches and progressive ocular neuropathy who underwent an endoscopic resection of a large sphenoid sinus mucocele resulting in immediate improvement of her neurological symptoms. The endoscopic endonasal transsphenoidal approach offers a minimally invasive method to manage and treat symptomatic sinus mucoceles.

KEYWORDS: Endoscopy, paranasal mucocele, endonasal approach, minimally invasive

Sinus mucoceles are slow-growing, benign, cystic lesions occurring in the paranasal sinuses. They are the most common expansile lesion of the sinuses, filled with mucous secreted by the epithelium of the paranasal sinuses. The mucocele usually occurs when the natural sinus ostium is obstructed by an inflammatory process but may also form as a result of tumor, trauma, or surgical manipulation. Left untreated, mucoceles may continue to expand and erode into the surrounding structures. The vast majority of these lesions arise from the frontal and ethmoid sinuses, with a minority of cases involving the maxillary or sphenoid sinuses. Isolated sphenoidal mucoceles occur infrequently, accounting for only $2 \%$ of paranasal mucoceles. ${ }^{1,2}$ Although rare, large mucoceles of the sphenoid sinus can become symptomatic due to the compression of proximal structures or the invasion of contiguous anatomic regions. ${ }^{3,4} \mathrm{We}$ present a case of a patient with a long-standing symptomatic sphenoid sinus mucocele whose symptoms rapidly resolved after a minimally invasive endoscopic decompression and marsupialization.

\section{CASE REPORT}

A 70-year-old woman was admitted with worsening complaints of frontal headaches, horizontal diplopia, and vertigo over the course of 6 months. Neuroophthalmologic examination demonstrated bilateral superotemporal visual field deficits to confrontation, bilateral abducens nerve palsies, and right eye ptosis. A brain magnetic resonance imaging (MRI) revealed a large $5 \times 3 \times 3-\mathrm{cm}$ cystic, ring-enhancing mass centered in the sphenoid sinus with a solid component along the planum and sella. The lesion displayed mass effect on the pituitary gland/stalk, optic chiasm, cavernous sinuses, and frontal lobes (Fig. 1). Computed tomography confirmed complete erosion of the sella, lateral sphenoid walls, and intrasphenoidal clivus. Pituitary function evaluation tested positive for
${ }^{1}$ Department of Neurological Surgery; ${ }^{2}$ Division of OtolaryngologyHead and Neck Surgery, George Washington University, Washington, District of Columbia.

Address for correspondence and reprint requests: Alan Siu, M.D., Department of Neurological Surgery, George Washington University, 2150 Pennsylvania Avenue, NW, Suite 7-420, Washington, DC 20037 (e-mail: askew01@gwu.edu).
Skull Base Rep 2011;1:23-26. Copyright (C) 2011 by Thieme Medical Publishers, Inc., 333 Seventh Avenue, New York, NY 10001, USA. Tel: +1(212) 584-4662.

Received: July 2, 2010. Accepted: September 15, 2010. Published online: April 4, 2011.

DOI: http://dx.doi.org/10.1055/s-0031-1275249.

ISSN 2157-6971. 
A
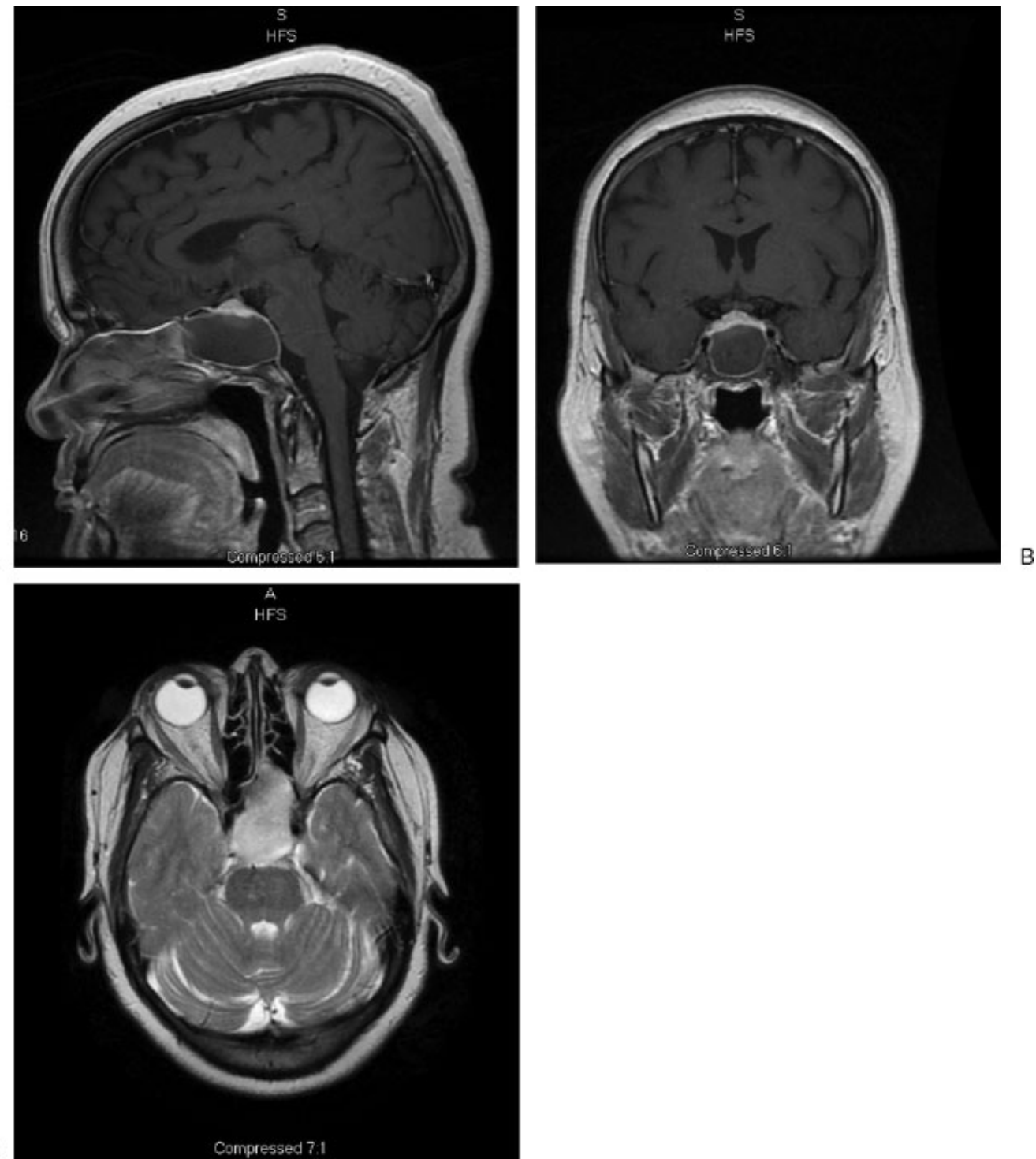

Figure 1 Preoperative magnetic resonance imaging of a 70-year-old woman with large cystic sellar mass with rim enhancement shown to be abutting the optic chiasm (A, B) superiorly. The hyperintensity on T2 (C) may be indicative of proteinaceous material. The left sphenoid sinus is also obliterated.

hypothyroidism. Differential diagnosis of this lesion included a pituitary tumor versus a mucocele, very unlikely to be a chordoma or meningioma.

The patient consented to a transsphenoidal endonasal endoscopic biopsy/decompression/resection of this enhancing mass. A wide bilateral sphenoidotomy with posterior septectomy revealed a large cystic lesion, under pressure, which was decompressed and drained. The surgical site was gently irrigated, and a solid thick mucoid component was curetted away from the planum sphenoidale and lateral opticocarotid recesses bilaterally. Further intracavity endoscopic exploration confirmed the presence of an extensive and complete erosion of the osseous structures with exposure of the planum sphenoidale and sellar and clival dura (Fig. 2). Intraoperative pathological exami- nation confirmed the preliminary diagnosis of a mucocele.

The patient's neurological deficits improved rapidly in the early postoperative period with significant amelioration of the diplopia and resolution of the headaches. Postoperative MRI demonstrated complete decompression of the optic chiasm, cavernous sinuses, and frontal lobes bilaterally (Fig. 3). Gram stains and cultures were unremarkable, and final pathological diagnosis was consistent with a mucocele (proteinaceous material with polymorphonucleate infiltrate).

\section{DISCUSSION}

Sphenoid sinus mucoceles comprise 1 to $2 \%$ of all paranasal mucoceles and are believed to be the result of 
A
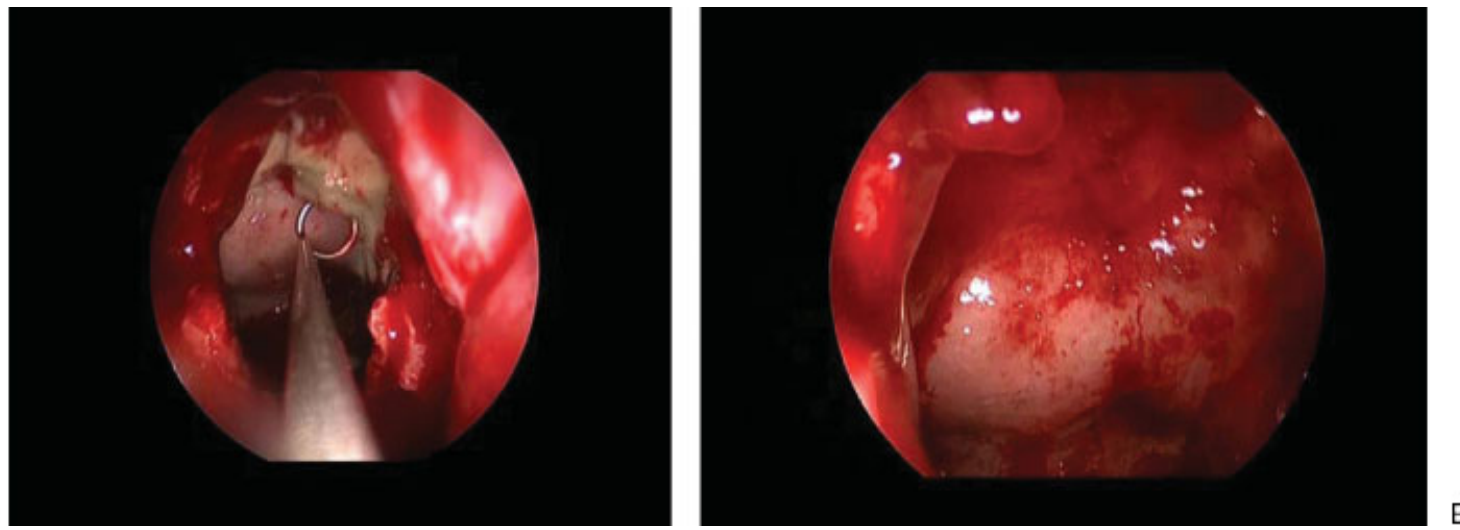

Figure 2 Intraoperative endoscopic imaging of the mucocele cavity.

A
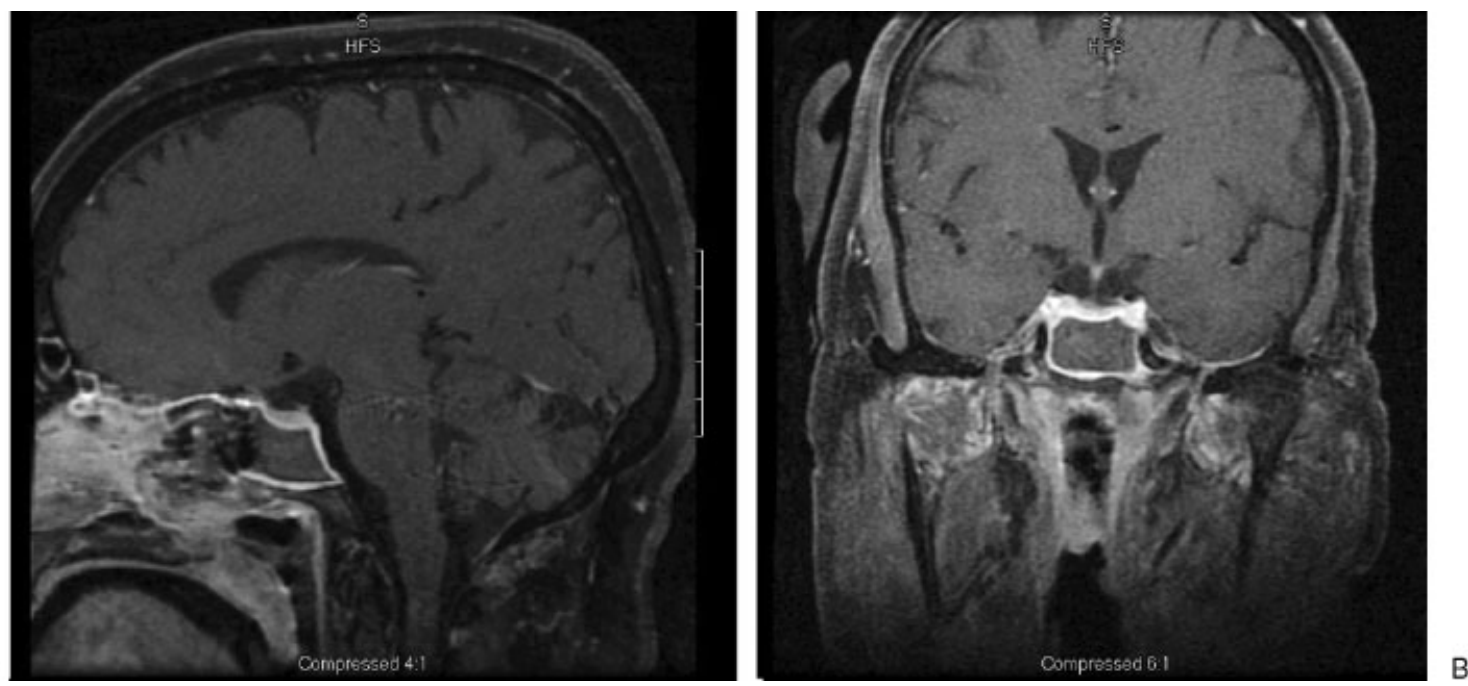

Figure 3 Postoperative magnetic resonance imaging indicating decompression of the optic chiasm with the marsupialization of the cyst. The patient noted immediate improvements with her vision and sixth nerve palsies.

submucosal edema or secretory duct and ostial obstruction. Approximately 140 cases have been reported in the literature, ${ }^{1,5}$ with headache and visual deficits being the most frequent presenting symptoms. ${ }^{6}$ Ocular symptoms occur as a result of compression and involvement of cranial nerves II, III, IV, and VI as the mucocele expands in its natural cavity.

Successful endoscopic management of mucoceles was first described by Kennedy et al in $1989 .{ }^{7}$ Several subsequent case reports have been described with similar radiographic decompression of cranial neuropathies to yield progressive symptomatic improvements. ${ }^{2,3,8-13}$ In our patient, the resolution of the cranial nerve palsies occurred in the immediate postoperative setting, an indication that the rapid diagnosis and decompression with marsupialization should yield good outcomes.

The adoption of the endoscope into the neurosurgical and skull base surgery armamentarium has allowed significant improvements in the field of minimally invasive neurosurgery. The endoscopic trans- sphenoidal approach offers many advantages from a surgical and patient perspective. The endoscope allows superior visualization, ability to look around corners, intracavity exploration, and greater illumination and magnification of the surgical field. The panoramic view of the resection cavity is enhanced by the added maneuverability and proximity of the focal point to the surgical field, thus minimizing the risks of incomplete resection due to poor visualization. In an initial cohort of 50 patients and a subsequent series of 160 cases involving intrasellar and suprasellar adenomas, Jho et al found that the endoscopic endonasal approach provided a quicker recovery, decreased discomfort, and a shorter hospital stay, with final surgical outcomes being comparable to that of microscopic transsphenoidal surgery. ${ }^{14-17}$ Other groups have published similar outcomes, ${ }^{18-21}$ and more recent comparisons of endoscopic procedures to traditional microsurgical techniques have shown comparable results without increased complications. $^{21-24}$ 


\section{CONCLUSION}

Our report details the rapid subjective and objective improvement in long-standing cranial neuropathies after successful decompression and marsupialization of a large expansile sphenoid sinus mucocele using a minimally invasive endonasal endoscopic approach. Endoscopic management of these lesions can result in dramatic and immediate recovery of long-standing neurological deficits.

\section{REFERENCES}

1. Kösling S, Hintner M, Brandt S, Schulz T, Bloching M. Mucoceles of the sphenoid sinus. Eur J Radiol 2004;51:1-5

2. Darouassi Y, Righini CA, Reyt E. Mucoceles of the sphenoidal sinus: a report of four cases and review of the literature. B-ENT 2005;1:181-185

3. Barat JL, Marchal JC, Bracard S, Auque J, Lepoire J. Mucoceles of the sphenoidal sinus. Report of six cases and review of the literature. J Neuroradiol 1990;17:135-151

4. Yokoyama T, Inoue S, Imamura J, et al. Sphenoethmoidal mucoceles with intracranial extension-three case reports. Neurol Med Chir (Tokyo) 1996;36:822-828

5. Righini CA, Darouassi Y, Boubagra K, Schmerber S, Reyt E. Sphenoid sinus mucocele of unusual aetiology and location. Rev Laryngol Otol Rhinol (Bord) 2006;127:165-170

6. Hejazi N, Witzmann A, Hassler W. Ocular manifestations of sphenoid mucoceles: clinical features and neurosurgical management of three cases and review of the literature. Surg Neurol 2001;56:338-343

7. Kennedy DW, Josephson JS, Zinreich SJ, Mattox DE, Goldsmith MM. Endoscopic sinus surgery for mucoceles: a viable alternative. Laryngoscope 1989;99:885-895

8. Khademi B, Gandomi B, Tarzi M. A huge sphenoid sinus mucocele: report of a case. Ear Nose Throat J 2009;88:E5

9. Loo JL, Looi AL, Seah LL. Visual outcomes in patients with paranasal mucoceles. Ophthal Plast Reconstr Surg 2009;25: 126-129

10. Mohammadi G, Sayyah Meli MR, Naderpour M. Endoscopic surgical treatment of paranasal sinus mucocele. Med J Malaysia 2008;63:39-40

11. Selvapandian S, Rajshekhar V, Chandy MJ. Mucoceles: a neurosurgical perspective. Br J Neurosurg 1994;8:57-61
12. Sinha BK, Adhikari P. Sphenoid sinus mucocele with blindness: a rare presentation. Nepal Med Coll J 2008;10: 204-206

13. Soon SR, Lim CM, Singh H, Sethi DS. Sphenoid sinus mucocele: 10 cases and literature review. J Laryngol Otol 2010;124:44-47

14. Jho HD. Endoscopic transsphenoidal surgery. J Neurooncol 2001;54:187-195

15. Jho HD, Alfieri A. Endoscopic endonasal pituitary surgery: evolution of surgical technique and equipment in 150 operations. Minim Invasive Neurosurg 2001;44:1-12

16. Jho HD, Carrau RL. Endoscopic endonasal transsphenoidal surgery: experience with 50 patients. J Neurosurg 1997;87: 44-51

17. Jho HD, Carrau RL, Ko Y, Daly MA. Endoscopic pituitary surgery: an early experience. Surg Neurol 1997;47:213-222; discussion 222-223

18. Cappabianca P, Cavallo LM, Colao A, de Divitiis E. Surgical complications associated with the endoscopic endonasal transsphenoidal approach for pituitary adenomas. J Neurosurg 2002;97:293-298

19. Cappabianca P, Cavallo LM, Colao A, et al. Endoscopic endonasal transsphenoidal approach: outcome analysis of 100 consecutive procedures. Minim Invasive Neurosurg 2002;45: 193-200

20. Duz B, Harman F, Secer HI, Bolu E, Gonul E. Transsphenoidal approaches to the pituitary: a progression in experience in a single centre. Acta Neurochir (Wien) 2008;150:1133-1138; discussion 1138-1139

21. Kabil MS, Eby JB, Shahinian HK. Fully endoscopic endonasal vs. transseptal transsphenoidal pituitary surgery. Minim Invasive Neurosurg 2005;48:348-354

22. Dehdashti AR, Ganna A, Karabatsou K, Gentili F. Pure endoscopic endonasal approach for pituitary adenomas: early surgical results in 200 patients and comparison with previous microsurgical series. Neurosurgery 2008;62:1006-1015; discussion 1015-1017

23. Jain AK, Gupta AK, Pathak A, Bhansali A, Bapuraj JR. Excision of pituitary adenomas: randomized comparison of surgical modalities. Br J Neurosurg 2007;21:328331

24. O'Malley BW Jr, Grady MS, Gabel BC, et al. Comparison of endoscopic and microscopic removal of pituitary adenomas: single-surgeon experience and the learning curve. Neurosurg Focus 2008;25:E10 